\title{
A Phenomenological Study on Nurses' Perception of Compensation Received During Covid-19 Pandemic
}

\author{
Dr. Dean Michael Aguon ${ }^{1}$ and Dr. Nam Phuong Le ${ }^{2}$ \\ ${ }^{1}$ Researcher, Ehrling Bergquist Clinic, USA \\ ${ }^{2}$ Faculty Member, University Canada West, Canada \\ *Correspondence: Dr. Nam Le, lpnam@hotmail.com
}

\begin{abstract}
The Covid-19 pandemic has created intense pressure on our society and the economy in many ways. Many industries were severely impacted, especially the healthcare industry. In this study, we conducted a qualitative phenomenological study to learn about the nurses' perception of their compensation during the pandemic. Since nurses are the critical front-line workers during the pandemic, it is vital to ensure their well-being in many aspects. Our study can help to improve the quality of the healthcare system at the same time, lower the turnover. During COVID-19, the nurses have been facing intense pressure on their mental health at work. Moreover, they believe that there should be more incentive in terms of financial and recognition for their work and receive more care from upper management.
\end{abstract}

KEYWORDS: Covid-19 pandemic, healthcare industry, nurses' compensation

\begin{abstract}
ARTICLE INFORMATION
Author(s): Dr. Dean Michael Aguon and Dr. Nam Phuong Le Received: 19 Oct, 2021; Accepted: 16 Nov, 2021; Published:27 Nov, 2021 e-ISSN: 2347-4696;

Paper Id: BMN-IJBMR-2021-76;

Citation: doi.org/10.37391/IJBMR.090407

Webpage-link:

https://ijbmr.forexjournal.co.in/archive/volume-9/ijbmr-090407.html
\end{abstract}

\section{INTRODUCTION}

COVID-19 has caused an unprecedented change in our global society. The first case of this novel coronavirus was documented in December 2019 in Wuhan, China [1]. In early March 2020, the World Health Organization (WHO) announced COVID-19 as the global pandemic [2]. Since it was first found, the number of cases has been growing exponentially. According to World odometer, the number of cases has grown rapidly from 987 on Feb 22, 2020 (earliest data) to surpassing 200 million cases worldwide as of August 2021 [3]. In addition, the number of deaths due to this virus also gets close to 4.5 million as of mid-August 2021. This highly infectious virus has negatively impacted economies, jobs, and people's lives, especially the healthcare industry [1]. The Covid-19 pandemic has caused strong pressure on the global health care system [4]. Many studies have confirmed the stress that the pandemic caused on front-line healthcare workers $[4,1,5]$. There are various concerns with the nurses about the working condition and being compensated for the high level of stress and anxiety that they have been experiencing $[6,7]$. There has been widespread dissatisfaction among nurses globally. Senek et al (2020) stated the leaver rate was very high for nurses. Nurses can be demoralized if they perceive missed care or lack of support. It is expected that the global healthcare system will have a shortage of 5.8 million nurses [8]. In this study, we would like to examine the nurses' perception of their compensation received during the Covid-19 pandemic. The result of the study will help healthcare leaders to understand the nurses' point of view to avoid failure in leadership. Thus, better policies can be introduced and implemented to improve the level of satisfaction among the nurses.

\subsection{Work stress among nurses during COVID-19 pandemic}

COVID-19 pandemic has created a substantial burden on the healthcare system and increased the level of stress among the front-line workers. Mo et al. (2020) has conducted a quantitative study on the stress level for Chinese nurses in Wuhan. They collected data by using online surveys from 180 nurses. The finding showed that the nurses were working under high pressure during the COVID-19 [2]. The result of Mo et al. (2020) is consistent with Arnetz et al. (2020), who conducted a qualitative study on the same topic in the United States. Arnetz and the team collected data using open-ended questions from 455 nurses in the United States. More than 50 percent showed vital concern related to their workplace during the pandemic. The level of stress for the nurses increased because they were exposed to a condition that "[threatens] their health, well-being, and ability to work" [4]. Due to the highly contagious and dangerous nature of the virus, many nurses were afraid of becoming infected. Moreover, observing critically ill and dying patients also contributed to their stress levels [4].

Another study in Italy concluded that both front-line and second-line health care workers experienced a high level of mental issues such as stress, depression, anxiety, and insomnia [9]. In Australia, Halcomb et al. (2020) has pointed out some other sources of stress for the nurses, including shortage of protective equipment, job security, compensation, and employment conditions [7]. The stress and other mental issues experienced by nurses around the world have been well documented in many other studies such as Chekole et al. (2020) in Ethiopia, De los Santos \& Labrague (2021) in the Philippines, and Engelbrecht, Heunis, \& Kigozi, (2021) in South Africa $[1,5,6]$. Beyond the workplace, many nurses are concerned about increasing the risk of infection for their children at home [6]. The psychological distress encountered if not treated properly can cause adverse effects on the long-term 
health of the nurses [6].

\subsection{Compensation in the healthcare industry}

The stress and burnout among nurses were considered a workplace hazard even before the COVID-19 pandemic [4]. A study before the COVID-19 pandemic suggested that the work condition and financial compensation are the critical factors in determining turnover for nurses [10]. Turnover problems of the nurses will increase healthcare organizations' costs from hiring, training, or having temporary labour [10]. Chen et al. (2015) also found that compensation will help improve job satisfaction among the nurses and thus help to improve the work attitude [11]. From the management perspective, employee job satisfaction will help to enhance organizational effectiveness [12, 13].

During the COVID-19 pandemic, financial support is one of the requests from the nurses in Halcomb et al.'s study. Many nurses were concerned about low pay. According to the nurses, fair pay is critical to improving nurses' ability to provide high-quality care during the pandemic. With fair compensation, the nurses will not feel "used and abused" [7]. Moreover, nurses feel the need for a guaranteed amount of work hours. Similar findings were found in Chekole et al.'s study; income and job security also contributed to nurses' stress levels in Ethiopia [6]. As a result, many nurses are looking for financial incentives to help them overcome mental distress [5].

\subsection{Dissatisfaction and turnover among nurses}

According to Savitsky, Radomislensky, and Hendel (2021) by increasing the level of satisfaction among nurses, it can help to reduce the turnover rate [14]. The authors found out that the lack of protective personal equipment also contributed to job low satisfaction among nurses. In their research, Savitsky et al. (2021) came up with an interesting finding which "the elevation of workload was not associated with lower occupational satisfaction" [14]. This finding is consistent with another research by Dwinijanti, Adhikara, and Kusumapradja (2020) which stated that workload and burnout can cause dissatisfaction among nurses; however, the higher among of workload did not cause a higher turnover. The nurses in the study indicated that the heavy workload is still reachable [15]. Another study by Labrague and de Los Santos (2021) pointed out that the fear of Covid-19 among nurses can cause job dissatisfaction and higher turnover [16]. Moreover, the psychological distress and fear of Covid-19 can come from a lack of adequate training. Therefore, according to the authors to increase job satisfaction and reduce turnover, the fear of Covid-19 should be addressed [16].

Said and El-Shafei (2021) found that nurses that directly deal with Covid-19 patients experienced a higher level of stress than other nurses [17]. The cause of stress can come from a higher workload and the working environment which includes dealing with many dead and dying patients. The nurses were not emotionally prepared to work under this condition. Many nurses reveal conflict with the supervisors due to the lack of supports. The stress level that the nurses were experienced can negatively affect the level of job satisfaction. Said and ElShafei (2021) continued to point out that the nurses were dissatisfied with the extrinsic rewards which include "financial and moral compensations" together with scheduling and heavy workload. According to the authors, employers can help to reduce turnover by decreasing the level of stress for the nurses [17].

\section{METHODOLOGY}

This is a qualitative phenomenological study. The central research question in this study is: What is the lived experience of the attitude of nurses of compensation received during COVID-19? According to Creswell (2013), this type of research explores the same phenomenon that a group of people experienced. The size can vary from 3 to 4 participants to 10 to 15 participants [18]. Data were collected between September and October of 2021 from five nurse employees in Omaha, Nebraska, United States. The participants were all involved in the practice of nursing during the COVID-19 pandemic. The nurses are labelled with pseudonyms as Participants $1-5$ to maintain confidentiality. The research team conducted virtual interviews at times convenient to the participants using the audio feature of Zoom. Before the start of each interview, the researcher confirmed the participant's consent to record the interview audio. Moreover, the researcher opened each interview session by explaining the purpose of the discussion and emphasized that any identifying information would be omitted. The research team ensured that participants knew that they were under no obligation to continue any or all the interviews and could leave the Zoom conference at any time.

\section{DISCUSSION OF THE FINDINGS}

Table 1 below summarizes the findings from interviews with the nurses. There are two major themes which are Safety and Community.

Table 1. Thematic Analysis Model

\begin{tabular}{|l|l|}
\hline Category & \multicolumn{1}{|c|}{ Main ideas } \\
\hline Safety theme & \multicolumn{1}{|c|}{$\begin{array}{l}\text { Complexities of a pandemic } \\
\text { Translating theory into simulation } \\
\text { Public education } \\
\text { Cross-training of nurses }\end{array}$} \\
\hline Politicization & $\begin{array}{l}\text { The mental strain on nurses } \\
\text { Long hours } \\
\text { Implantation of ideas without proper } \\
\text { planning }\end{array}$ \\
\hline Barriers & $\begin{array}{l}\text { Patient idea systems } \\
\text { The gap in early identification } \\
\text { The gap in the incorporation of nurse's } \\
\text { knowledge and skills }\end{array}$ \\
\hline Community theme \\
\hline Self-care & $\begin{array}{l}\text { Need for normalcy } \\
\text { Hope } \\
\text { Effective leadership }\end{array}$ \\
\hline $\begin{array}{l}\text { Social } \\
\text { determinants }\end{array}$ & $\begin{array}{l}\text { Mental health } \\
\text { Attitude about belonging } \\
\text { Trust }\end{array}$ \\
\hline
\end{tabular}




\subsection{Safety theme}

The safety theme was first to emerge. The participants often acknowledge the need for additional training during a pandemic, the need for clear communication and less politicization, and the reduction of barriers in healthcare.

What has been the impact of COVID-19 on your daily workload?

Participants in this study have indicated a sudden increase in the amount of work that they have been facing since the beginning of the pandemic. For instant, participant 1 described the immediate impact COVID-19 had on the organization's routine, the influx of patients, and the need for additional staff members. This participant also expressed how individual roles changed and how staff members had to do more. The participant identified the complexities of training new staff as information on COVID-19, the prevention, and the treatment was not centralized. This finding is consistent with another study by Shen et al. (2020), which stated the "global healthcare systems have become overwhelmed" due to the pandemic [19].

In a similar pattern, participant 2 also expressed the shift in daily workload activities. The participant explained how personal goals had to be put on hold to handle the pandemic adequately and how much the healthcare facility needs nursing support. The participant moved through various clinics to fulfill the need of COVID patients. The participant indicated it is not just the patient care that has added to the workload, but the constant training required to stay updated on the virus.

Has your organization established a training program to assist you in caring for COVID-19 patients?

Many participants in this study received some forms of training related to the pandemic; however, since this is a new disease, there is not enough information that can be used for training. Many nurses hope more training should be in place to support them. Participant 5, who has been in the nursing field for five years, explained that pandemics are taught during formal training, but simulation training would be beneficial. The participant expressed that COVID-19 prevention and treatment protocols were delivered using on-the-job training. The participant indicated that the protocols had been changed often due to influences in sciences and policy.

Participant 2 added that the training received was through onthe-job training. Further expressed was the need to stay up to date using online resources and how nurses have added to the training platform by sharing additional knowledge acquired. Moreover, participant 3 indicated that training remains at the forefront but goes beyond training for COVID-19. The participant expressed that the organization's training encompasses teaching nurses about self-care and taking care of patients. The participant additionally expressed the desire of the organization to invest in more simulation training in the future.

Huang et al. (2020) stated that even with intensive training, sometimes nurses are not aware of their exposure to the risk due to the stress that they are facing. As a result, the management of the healthcare organization needs to reduce the level of stress that nurses are facing. This can help to improve the effectiveness of training [20].
The healthcare workforce providing for patients with COVID, in general, experiences the highest risk of contracting the virus. How has this increased risk impacted your willingness to serve in the field of nursing? Through the pandemic, many nurses were concerned about their safety and the safety of their loved ones. Participant 1 discussed the concerns of keeping self and family protected against the COVID-19 disease. Although precautions are taken when working in the healthcare setting, such as wearing personal protective equipment and vaccinations, a risk of contamination takes place when going home. The participant articulated how this risk was heightened when the others did not perceive the virus as substantial. This is consistent with Chekole et al. (2020)'s finding that the nurses were worried about passing the disease to their children [6].

Participant 2 also showed concerns regarding risk came from the lens of the unknown regarding COVID-19. The participant expressed the timeframe of incubation of the virus before it can begin to present as symptoms and how this can lead to further infection of other members. The participant explained that the risk is from the disease and the subsequent aspect of potentially dying alone without loved ones at the bedside. This led to the participant questioning continuation of a career in nursing.

Regarding the management response to the risk, participant 4 discussed the risk from the perspective of ineffective leadership. The participant expressed the pressure of quick implementation of guidance and how this pressure led to longer work hours and stress, impacting employees' health. As Huang et al. (2020) stated, a scientific and practical shift schedule can help to reduce the nurse shortage and the workload. Therefore, it is suggested that leadership review the shift schedule to avoid prolonged working hours [20].

\subsection{Community theme}

After analyzing the interviews, the nurses spoke of many challenges faced during COVID-19. Within these challenges, the theme of the community started to emerge. They spoke of the need for self-care and the social determinants of mental health, attitude about belonging, and trust.

Given your role during the COVID-19 pandemic, have you been compensated appropriately given the needed care for these patients?

The participants provided various ideas for compensation, including paid vacation, reimbursement for education, governmental bonus. However, the participants focus on better serving each other through self-care, open communication, and staying safe. Participant 5 mentioned the essential role nurses served throughout this pandemic. The participant delineated the role as a responsibility. This participant went beyond the patient care side and flowed into keeping the medical team together and finding moments of normalcy within the pandemic's chaos.

Participant 2 also discussed the nurse's role within the healthcare setting before verbalizing compensation was lacking. The participant spoke regarding the long work hours performed, usually with limited or no breaks. The participant 
felt proud to be a part of the nation's history of finding treatment and preventative measures. Similarly, participant 3 expressed additional compensation for nursing professionals is required. The participant stated that although the compensation can't help forgetting about the psychological trauma experienced throughout the COVID-19 pandemic, it would be beneficial to show appreciation.

The participants provided varied ideas for compensation consisting of paid vacation, payment for education, governmental bonus. However, the participant's consensus was that the current focus is on better serving one another through self-care, open communication, and staying safe. The responses from participants in this study are consistent with Chen et al. (2015) and Halcomb et al. (2020), which stated that compensation could help to improve work satisfaction among nurses and thus improve their performance [7, 11].

During a pandemic, the work environment can become extremely risky. To ensure job satisfaction, the impact of incentives can play a significant role. What is your view on the incentives received for your work during the pandemic? Do you believe more should be done to incentivize your work?

Nurses in this study agree that there should be more incentive for them during this hardship besides financial reward. Participant 4 mirrored her time throughout the pandemic as if giving it thought for the first time. The participant denied receiving any incentives for the extra task performed throughout the pandemic. However, the participant explained the enjoyment that came from developing new ideas to fulfill the wants of the patients. The participant highlighted the importance of respectful treatment of staff instead of paying as key to retaining staff.

In addition, participant 5 accessorial to the consensus of alternate incentives instead of specializing in pay. The participant believed it had been essential to focus on guaranteeing the psychological state of nurses well on the far side COVID-19 pandemic. The participant reminded the questioner of delayed stress and felt when nurses are given breathing room to reflect will ultimately cause symptoms the same as a post-traumatic stress disorder.

\section{CONCLUSIONS}

Based on the research, it is clear that this pandemic is a sudden event that nurses were not prepared for. As a result, it created a burden on them to perform their job. This pandemic has created a new situation with many unpredictable variables. Thus, training cannot be adequate; the nurses had to learn to adapt to the situation independently. In addition, nurses had to learn from each other due to the lack of information to incorporate into formal training. Consistent with previous literature, the participants in this study also worry about transmitting the disease to their children who are not yet vaccinated. Some participants even question whether they should stay in their position. This can cause turnover in the healthcare industry.
Many nurses in this study feel that their job is vital for the healthcare industry and positively impacts the patients. Regarding the current level of compensation, the nurses stated that it is not adequate. The nurses are hoping for more incentives. However, not all nurses stress financial rewards, but they expect the management and government to care for their mental health and recognize their work. We would suggest the government and healthcare organizations come up with policies to improve the working condition of the nurse to help reduce their mental stress and recognize their work. For future research suggestions, it can be helpful to conduct similar research in a different geographical area to generalize the finding.

\section{REFERENCES}

[1] De los Santos, J. A. A., \& Labrague, L. J. (2021). The impact of fear of COVID-19 on job stress, and turnover intentions of frontline nurses in the community: A cross-sectional study in the Philippines. Traumatology, 27(1), 52.

[2] Mo, Y., Deng, L., Zhang, L., Lang, Q., Liao, C., Wang, N., Qin, M., \& Huang, H. (2020). Work stress among Chinese nurses to support Wuhan in fighting against the COVID-19 epidemic. Journal of nursing management, 28(5), 1002-1009.

[3] Worldodometer (2021). Coronavirus cases. Retrieved on Aug 22, 2021, from: https://www.worldometers.info/coronavirus/

[4] Arnetz, J. E., Goetz, C. M., Arnetz, B. B., \& Arble, E. (2020). Nurse reports of stressful situations during the Covid-19 pandemic: qualitative analysis of survey responses. International journal of environmental research and public health, 17(21), 8126.

[5] Engelbrecht, M. C., Heunis, J. C., \& Kigozi, N. G. (2021). PostTraumatic Stress and Coping Strategies of South African Nurses during the Second Wave of the COVID-19 Pandemic. International Journal of Environmental Research and Public Health, 18(15), 7919.

[6] Chekole, Y. A., Yimer Minaye, S., Mekonnen Abate, S., \& Mekuriaw, B. (2020). Perceived stress and its associated factors during COVID-19 among healthcare providers in Ethiopia: a cross-sectional study. Advances in Public Health, 2020.

[7] Halcomb, E., Williams, A., Ashley, C., McInnes, S., Stephen, C., Calma, K., \& James, S. (2020). The support needs of Australian primary health care nurses during the COVID-19 pandemic. Journal of nursing management, 28(7), 1553-1560.

[8] Senek, M., Robertson, S., Ryan, T. et al. (2020). Determinants of nurse job dissatisfaction - findings from a cross-sectional survey analysis in the UK. BMC Nurs 19,88. https://doi.org/10.1186/s12912-020-00481-3.

[9] Rossi R, Socci V, Pacitti F, et al. Mental Health Outcomes Among Frontline and Second-Line Health Care Workers During the Coronavirus Disease 2019 (COVID-19) Pandemic in Italy. JAMA Netw Open. 2020;3(5):e2010185. doi:10.1001/jamanetworkopen.2020.10185.

[10] Mahoney, C. B., Lea, J., Schumann, P. L., \& Jillson, I. A. (2020). Turnover, burnout, and job satisfaction of certified registered nurse anesthetists in the United States: Role of job characteristics and personality. AANA Journal, 88(1), 39-48.

[11] Chen, F., Yang, M., Gao, W., Liu, Y., \& De Gieter, S. (2015). Impact of satisfactions with psychological reward and pay on Chinese nurses' work attitudes. Applied Nursing Research, 28(4), e29-e34. 
[12] Liton, R., \& Dawlat, K.A.K.M. (2020). Nurses' Job Satisfaction at the Southeast District, Chattogram in Bangladesh: A Crosssectional Study. International Journal of Caring Sciences, 13 (2), 938-949.

[13] Koys, D. J. (2001). The effects of employee satisfaction, organizational citizenship behaviour, and turnover on organizational effectiveness: A unit-level, longitudinal study. Personnel Psychology, 54(1), 101-114.

[14] Savitsky, B., Radomislensky, I., \& Hendel, T. (2021) Nurses' occupational satisfaction during Covid-19 pandemic, Applied Nursing Research, Volume 59, 2021, 151416, ISSN 0897-1897, https://doi.org/10.1016/j.apnr.2021.151416.

[15] Dwinijanti, L., Adhikara, M. A., Kusumapradja, R. (2020). Job satisfaction and turnover intention among public sector nurses: Is workload and burnout the issue? JEMA: Jurnal Ilmiah Bidang Akuntansi dan Manajemen, 17(1), 67-77.

[16] Labrague, L. J., \& de Los Santos, J. A. A. (2021). Fear of Covid-19, psychological distress, work satisfaction and turnover intention among frontline nurses. Journal of nursing management, 29(3), 395-403.
[17] Said, R.M., \& El-Shafei, D.A. (2021) Occupational stress, job satisfaction, and intent to leave: nurses working on front lines during COVID-19 pandemic in Zagazig City, Egypt. Environ Sci Pollut Res 28, 8791-8801. https://doi.org/10.1007/s11356020-11235-8.

[18] Creswell, J. W. (2013). Qualitative Inquiry and Research Design: Choosing among Five Approaches ( $3^{\text {rd }}$ edition). Sage Publications: Thousand Oaks, CA, USA.

[19] Shen, X., Zou, X., Zhong, X., Yan, J., \& Li, L. (2020). Psychological stress of ICU nurses in the time of COVID-19.

[20] Huang, L., Lin, G., Tang, L., Yu, L., \& Zhou, Z. (2020). Special attention to nurses' protection during the COVID-19 epidemic.

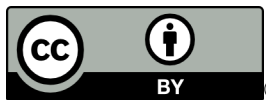

2021 by the Dr. Dean Michael Aguon and Dr. Nam Phuong Le. Submitted for possible open access publication under the terms and conditions of the Creative Commons Attribution (CC BY) license (http://creativecommons.org/licenses/by/4.0/). 